\title{
The Use of Benefit Transfer to Estimate the Recreational and Touristic Value of Two Wooded Areas in Tuscany
}

\author{
Francesco Riccioli ${ }^{1}$, Roberto Fratini ${ }^{1}$, Jean-Pierre El Asmar ${ }^{2}$, Toufic El Asmar ${ }^{1}$ \\ ${ }^{1}$ Department of Agricultural and Forest Economics, Engineering, Sciences and Technologies, University of Florence, Florence, Italy; \\ ${ }^{2}$ Faculty of Architecture Art and Design, Notre Dame University-Louaize, Zouk Mosbeh, Lebanon. \\ Email: \{francesco.riccioli, roberto.fratini\}@unifi.it, toufic.elasmar@gmail.com,jasmar@ndu.edu.lb
}

Received November $3^{\text {rd }}, 2011$; revised December $16^{\text {th }}, 2011$; accepted December $23^{\text {rd }}, 2011$

\begin{abstract}
The holistic role of forests going beyond the economic function, identified in timber production, substantiates the evaluation of forests' social and environmental dimensions. Consequently, biodiversity, landscape, hydro-geological security, and maintenance of cultures and traditions are among the manifold issues to be addressed in dealing with forests. Touristic and recreational role of forests is also associated with the disproportionate development of human activities, sources of pollution often correlated to a reduced quality of life. This paper aims at applying the benefit transfer methodology to estimate (from a financial point of view) the recreational and touristic value of wooded areas. The proposed approach relies on an extensive literature review including earlier published books, project' reports, scientific journals, and conference proceedings addressing the economic evaluation of forests. The reviewed methodologies are then rationally synthesized, adapted, and applied on two case studies in Tuscany, in an attempt to assign a value to forest's systems; however, only the recreational and touristic dimensions are considered. The ultimate purpose of this work is to emphasize aspects that were not yet properly considered in the financial appraisal of wooded areas, for a balanced management of natural resources avoiding deterioration and neglect.
\end{abstract}

Keywords: Benefit Transfer; Touristic Recreational Value; Forest’s Resources; Environmental Goods

\section{Introduction}

A proper assessment of forest resources, cannot fail to consider the various aspects (functions) that characterize the forests: tangible and intrinsic as well as intangible. This is referred as the social value of resource, which focuses on the maximization of the community's well being rather than the personal well-being. The community is the interpreter of the rights of the future generations and of the non human species. Accordingly, the forest is treated as a component within a more complex "environmental system", difficult to assess. From an economic point of view the concept of "environmental good" is combined with that of public good, and both characterized by the absence of the market and by not being subject to property rights. However, for these assets market value cannot be determined, and accordingly it is essential to consider a range of tangible and intangible aspects. Future generation's use and enjoyment of the goods produced by this environmental system and the protection and preservation of animal and vegetal species should be considered in the computation. Accordingly, the concept of Total Economic Value (VET) is introduced. The VET allows dealing with problems related to the impossibility using the criteria of cost and market price to estimate these types of goods.

The literature categorized the various aspects determining the total economic value of forests into three dimensions: the social, the economic, and the environmental. [1-4] identify aspects of lumber and other wood products' production, protection of the hydro-geological resources, the carbon fixation, the biodiversity preservation, and the recreational tourism activities.

Furthermore, from an operational point of view, the methodologies used to estimate the environmental assets ${ }^{1}$ are divided into two groups: the non-monetary and monetary valuations. Leaving aside the latter, for which we refer to specialized texts for further study ${ }^{2}$, this work is based on the methods resulting in monetary outcomes: these can essentially be distinguished into direct and indirect (contingent assessment and modeling techniques) belonging to the category of Benefit Transfer. Being a subject of large and countless open discussions, the assessment of the forests, for this work, is limited only to the evaluation of tourist recreational function, assessed

\footnotetext{
${ }^{1}[5,6]$ only to cite few examples.

${ }^{2}$ The Multi Criteria Analysis and the Environmental Impact Assessment are methodologies resulting in non-monetary outcomes [7-10].
} 
by applying the methodology of Benefit Transfer. The method is applied on two case studies in Tuscany, a region of central Italy: the wooded areas of Garfagnana and the Casentino National Park (Casentinese wooded areas).

\section{Adopted Methodology}

The Benefit Transfer methodology [5,11,12] aims mainly at the use or "transfer" of data from a "study site" to a "policy site", or the transposition of data from an area for which information are obtained through analysis based on primary research resources (study site) to another area for which the information are not available or limited (policy site) [13].

This methodology relies on an extensive review of the investigations conducted in the territory (in this case the Italian territory) concerning the monetary estimation of forests' resources. The degree of reliability of the estimation depends mainly on the availability of data and the level of harmony between the two areas which must have at least similar characteristics. Benefit Transfer includes four methods as follows:

- Single point estimate transfer;

- Average value transfer;

- Demand and benefit function transfer;

- Meta analysis function transfer.

Through the first two methods, belonging to the category of "value transfer", study site's single values or medium values are directly relocated to policy site. Through the third and fourth methods, belonging to the category of "function transfer", demand functions or regression analysis functions of study site are relocated and adapted to policy sites.

The first phase of this work consisted of a literature review to collect the necessary elements for the analysis of the tourist recreational benefits of the two areas of study: approximately one hundred papers published in refereed journals ${ }^{3}$, conference proceedings, and dissertations on forests' evaluation were reviewed.

In order to determine the variables, considered to be important and relevant for this research, the criterion for selection the most appropriate publications was based on both the region where the study was performed and the estimation method used (essentially Contingent Valuation and Travel Cost Method). In the second phase of this work, the annual value of tourist recreational area was calculated for the two study areas, applying two methods: the Single-Point Estimate Transfer and the Benefit Function Transfer.

\section{Study Areas}

A review of the Italian literature relevant to forests' esti-

${ }^{3}$ Among the refereed journals reviewed: Aestimum, L'Italia Forestale e Montana, Estimo e Territorio, Sherwood, Monti e Boschi, Rivista di Economia Agraria. mation identified two different typologies of forests located in Tuscany region, central Italy (Figure 1).

First area is Garfagnana that is a typical and dense wooded zone, while second area is represented by Casentinesi Forests that are a national park (Figure 2).

The Garfagnana is a typical example of wooded zone placed in an area of particular environmental value. The area's touristic attraction is focused on the discovery of its natural heritage, Garfagnana is an historical region of Italy, today part of the province of Lucca in the Apennines, in northwest Tuscany, and it is one of the rainiest regions of Italy, so it is largely covered by forest vegetation (mainly Chestnut, Oak and Pine). It is a mountainous region of Tuscany located between the Apuan Alps the main part of the Apennines. The total area is 53,377 hectares of which 38,032 ha (71.25\%) are occupied by the

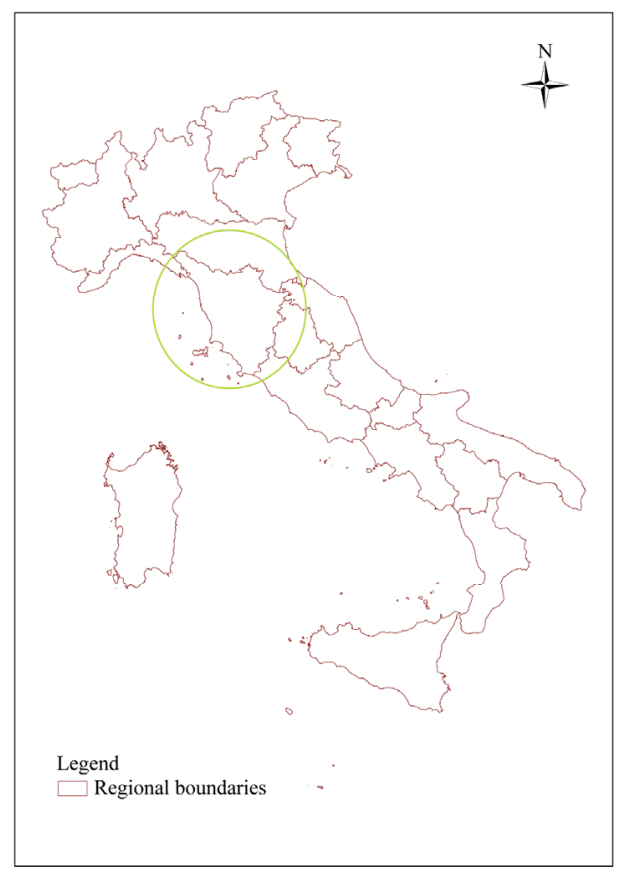

Figure 1. Study areas.

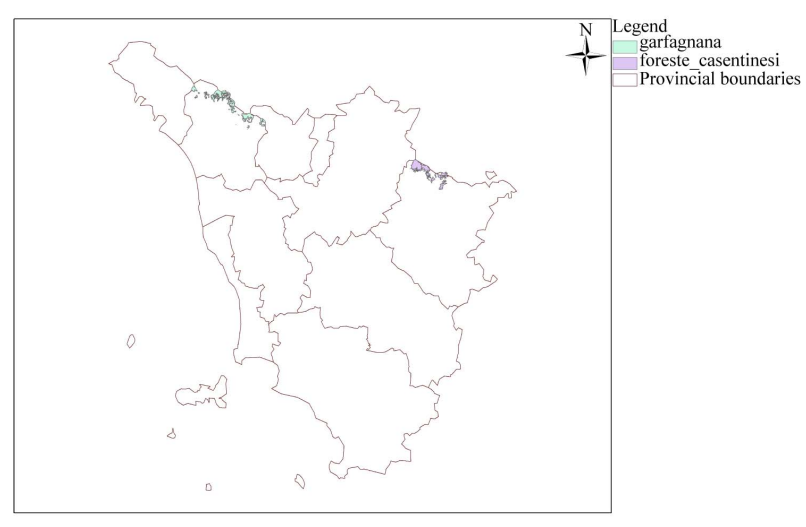

Figure 2. Study areas in detail. 
forest. The native trees are mostly deciduous, the most common being Chestnut, it is common to see pine in the region.

The Foreste Casentinesi (or Casentinesi forests), an integral part of the National Park holding the same name, offer the opportunity to estimate a famous typology of forests, able to attract a significant number of visitors every year, and which use is governed by forests' preservation and environmental protection. The Parco Nazionale delle Foreste Casentinesi, Monte Falterona, Campigna is a National Park in Italy. The whole area covers about 365 square kilometers (about $35.000 \mathrm{ha}$ ), on the two sides of the Apennine watershed between Romagna and Tuscany, and is divided between the provinces of Forlì Cesena, Arezzo and Florence. The forest extends around the long ridge, descending steeply along the parallel valleys of the Romagna side and more gradually on the Tuscany side. It slopes moderately, especially in the Casentino area, which slopes down gradually to the broad valley of the Arno River. The forest is dominated mainly by hornbeams, turkey oaks, sessile oaks and chestnut woods.

\section{Total Touristic Recreational Value Estimation}

The recreational aspect of forests is based on a variety of activities ranging from hiking, bird watching, mountain biking, the collection of non-forest products etc. as well as hunting which is considered an important aspect of these activities. Considering accordingly the total touristic recreational value $\left(\mathrm{B}_{\text {trt }}\right)$ as the sum of the benefits deriving from touristic activities $\left(B_{t}\right)$ (including in this case all the above mentioned forest activities however excluding hunting activity) and the activities relating to hunting $\left(\mathrm{B}_{\mathrm{av}}\right)$.

\subsection{Touristic Benefit Estimation $\left(B_{t}\right)$}

\subsubsection{Garfagnana}

To estimate the touristic benefit in the area of Garfagnana the single point estimate transfer, using the benefit previously determined in the study by [14] for the same study area, was used. The value has been estimated, in the previous study, through the Travel Cost Method [15] and [16]. The method is based on the cost of the trip, by a generic user, from the town of residence to the park in question. This cost will be used to replace the cost of the asset value. The main purpose is to establish the relationship between the number of visitors to the park and the costs incurred by the latter: this will enable us to create the demand curve for recreation. To do so, the whole estimate of the recreational demand of the whole experience is done in a first stage; the demand curve inherent in the recreation site is then developed. This methodology presents two types of approaches, one related to the zone and one that is individual. For the purpose of this study the first approach was implemented. The data was grouped by area of origin: This way we were able to determine the relationship between the samples of frequency $(\mathrm{K})$ to the park and the average costs incurred to reach the park from area of origin $\mathrm{j}$ previously created by the subdivision of the catchment area (Formula (1)).

$$
K=\frac{v_{j}}{A_{j}}
$$

where,

$\mathrm{K}$ = sample frequency;

$v_{j}=$ number of visits to the zone of origin $j$;

$A_{j}=$ number of dwellers in the zone of origin $j$.

The estimation of the relation between samples of frequency and rates of travel costs is done through a simple linear regression of the transformed original data. The model applied in the work of [14] is based on a double logarithm (Formula (2)).

$$
\ln \mathrm{v}=\mathrm{a}+\ln \mathrm{c}
$$

where,

$$
\begin{aligned}
& \ln =\text { natural logarithm; } \\
& \mathrm{v}=\text { number of visits; } \\
& \mathrm{a}=\text { intercept of the regression; } \\
& \mathrm{c}=\text { cost of the trip. }
\end{aligned}
$$

The average travel cost from the town of origin, was obtained by multiplying the average operating cost per kilometer per $\mathrm{car}^{4}$, by the distance of the town of origin from the examined park, divided then by the average number of visitors carried. Allowing then the homogeneity of the consumers' reactions, new frequency samples have been determined, due to hypothetical increases in travel costs, obtaining therefore an estimate of the aggregate demand function for the recreational activity under study (Formula (3)).

$$
v(p)=\sum_{j=1}^{m} v_{j}(p)=\sum_{j=1}^{m} A_{j} f\left(c_{j}+p\right)
$$

where;

$\mathrm{v}(\mathrm{p})=$ number of visits in relation to hypothetical increases in travelling cost;

$\mathrm{v}_{\mathrm{j}}(\mathrm{p})=$ number of visits from origin areas $\mathrm{j}$ with respect to costs' increase;

$A_{j}=$ number of dwellers in the area of origin $j$;

$\mathrm{c}_{\mathrm{j}}=$ cost of trip from the origin zone $\mathrm{j}$;

$\mathrm{p}=$ computed cost.

Finally, steps were taken to calculate the touristic value of the environmental good $\left(\mathrm{B}_{\mathrm{t}}\right)$, by solving the integrity of the area under the demand curve for recreation (Formula (4)).

${ }^{4}$ Calculated as the average of the costs of transportation to the park using the tables of the Automobile Club of Italy (ACI) available online at: http://servizi.aci.it/CKInternet/SelezioneModello [last accessed October 4, 2011]. 


$$
\mathrm{B}_{\mathrm{t}}=\int \mathrm{v}(\mathrm{p}) \mathrm{dp}
$$

The use of the ACI (refer to footnote 4) tables, previously mentioned and updated to 2011, to calculate transportation costs allowed to update the data and conesquently the whole analysis: the average cost per kilometer per car amounts to $0.50 € / \mathrm{Km}$ and the annual value for outdoor recreation was higher than 686.000 euro $^{5}$ (Table 1).

\subsubsection{Casentinesi Forests}

In this case it was impossible to apply the Single point estimate transfer, because the only work found in the literature on the Casentino is by [17], and is only limited to a examination on hikers. The Benefit function transfer method was used to understand all the possible users of the park. Based upon this method the function of regress analysis developed by [14] was applied on Garfagnana. The regression curve was adapted on the Casentinesi Forests by incorporating what follows. Firstly, a buffer zone was estimated around the study areas (municipalities) and the users of the park (residents of the municipalities) affected by this buffer ${ }^{6}$ zone. The distance from the park was calculated for each town (the capital of the town was made to coincide with its core area) ${ }^{7}$. The cost of the trip was calculated based on the average exercise cost per kilometer per car.

As previously mentioned (Formula (2)), taking into consideration the regression function used by [14] being a double logarithm, the annual touristic benefit $\left(\mathrm{B}_{\mathrm{t}}\right)$ in the Casentino area is illustrated in Formula (5).

$$
\mathrm{B}_{\mathrm{t}}=\sum \mathrm{v}^{*} \mathrm{c}_{\mathrm{add}}
$$

where;

$\mathrm{v}=$ number of annual visits estimated through regression $\exp (\mathrm{a}+\mathrm{b} *(\operatorname{Ln} \mathrm{c}+\mathrm{p})) * \mathrm{~A}$;

$\mathrm{a}=$ intercept of the regression;

$\mathrm{b}=$ angular regression coefficient;

$\mathrm{c}=$ cost of the visit;

$\mathrm{p}=$ additional costs of the visit;

$A=$ number of dwellers of user's town of origin.

This analysis quantified the touristic benefit of the Casentinesi Forests to approximately 834.000 euro per year (Table 1).

\subsection{Estimation of Benefit from Hunting Activity (Bav)}

The values relative to the benefits from hunting activities

${ }^{5}$ The analysis conducted in 1987 and bearing value in pounds, estimated the cost of operating in 340 Italian old lira/km and the annual benefit for recreation 468.508.000.00 Italian old lira.

${ }^{6} \mathrm{~A}$ buffer zone of $100 \mathrm{Km}$ was considered as an example.

${ }^{7}$ The distances were estimated using the algorithm proposed online by Google Maps (Map data (C2011 Tele Atlas). It is based on largely aknowledged international standards cocerning Maps' denomination and mapping conventions; i.e. the ISO-3166 standard, acknowledged by the UN Statistics Division for the denomination of countries and zones.
Table 1. Estimation processes adopted and results of the analysis (Values are expressed in euro per year).

\begin{tabular}{ccccc}
\hline \multirow{2}{*}{ Study Area } & \multicolumn{2}{c}{ Touristic Benefit } & $\begin{array}{c}\text { Hunting } \\
\text { Activity Benefit }\end{array}$ & $\begin{array}{c}\text { Recreational } \\
\text { Touristic } \\
\text { Benefit }\end{array}$ \\
\cline { 2 - 4 } & $\begin{array}{c}\text { Single } \\
\text { point }\end{array}$ & $\begin{array}{c}\text { B. function } \\
\text { transfer }\end{array}$ & Single point & - \\
\hline Garfagnana & 686.041 & - & 61.532 & 747.573 \\
F. Casentinesi & - & 834.766 & 4.288 & 839.054 \\
\hline
\end{tabular}

were calculated for the two study areas, using the Single point estimate transfer based on a previous estimation by [18]. The study consisted of a developing a Contingent Valuation (CV) to find the benefit from hunting activities in the Province of Florence.

The CV is a methodology based on the creation of a virtual market of the good, subject of study, through the use of questionnaires and interviews aimed essentially at understanding the availability to pay a sum of money to realize the project and avoid damages, and the availability to accept a sum of money for the non realization of the project and for the incurred environmental damages.

The availability to pay or to accept is based on the concept belonging to the economy of the benefit wellbeing of the consumer that relates the market price with the overflow of the consumer as shown in the Formula (6).

$$
\mathrm{B}_{\mathrm{c}}=\mathrm{P}+\mathrm{S}_{\mathrm{c}}
$$

where;

$$
\begin{aligned}
& \mathrm{B}_{\mathrm{c}}=\text { consumer's benefit; } \\
& \mathrm{P}=\text { cost; } \\
& \mathrm{S}_{\mathrm{c}}=\text { consumer's overflow (this is meant, in Marsha- }
\end{aligned}
$$
llian sense, the difference between the quantity of money that the consumer would be willing to pay for certain amount of property and the amount that is actually paid).

The benefit of the consumer corresponds to the utility derived from the use of the property. In other words it is also defined as the willingness to pay for a particular good, or as the willingness to accept giving-up the improvement of the utility, or to accept the degradation of the overall utility.

A questionnaire is generally used, in which the questions central to the estimation of the DAP and the DAA are made in one of the following ways:

- Open-ended questions: maximum willingness to pay for a good (or minimum availability to accept compensation for the lack of the good) without any suggestions; this method results in estimation difficulty by the respondent, and it is accordingly very much used;

- Close-ended in binary format (dichotomous choice) questions: the binary mode overcomes the problems arising from any failure of the respondent to give a precise value to an asset of which he/she might have little or no familiarity. It also prevents the influence 
of the initial value payment imposed by the mechanism of auction. Generally, the proposed values should vary among the samples interviewed in accordance with rules;

- Guided open-ended questions: the choice of the respondent is limited to a payment card with decreasing ranges of monetary amounts;

- Payment ladder (or card): as above, with increasing monthly and annual amounts; the respondent chooses (checks) "V" all a values from a below list, that he/she would be willing to pay, and with an " $X$ " all those that he/she would not be willing to pay;

- Bidding game based on repeated offers (auction).

[18], have estimated the economic value of hunting in the province of Florence through a contingent valuation using an approach based on repeated offers (bidding game) on a sample of 712 respondents on three types of hunting: sedentary, ungulates, and migratory. The hunters were required to express the maximum willingness to pay the increase of the cost of the hunting license. This analysis resulted in an average annual willingness to pay (DAP) equal to 616 euro $^{8}$ per hunter. Depending on the number of hunters present in the target ${ }^{9}$ areas of hunting (ATC), and the relative hunting surfaces, the average willingness to pay for ATC has been estimated (Formula (7)).

$$
\mathrm{DAP}_{\text {atc }}=\mathrm{DAP}_{\mathrm{i}} * \mathrm{~S}_{\text {atci }} * \mathrm{~N}_{\mathrm{ci}}
$$

where;

$\mathrm{DAP}_{\text {atc }}=$ average willingness to pay for ATC;

$\mathrm{DAP}_{\mathrm{i}}=$ average willingness to pay for hunting activity of the hunter i per one acres;

$\mathrm{S}_{\text {atci }}=$ hunting surfaces of the ATC I;

$\mathrm{N}_{\mathrm{ci}}=$ number of hunters in the ATC $\mathrm{i}$.

These benefits were subsequently applied to the hunting area falling in each area of study: approximately 2900 acres in the woods of Garfagnana and 700 acres in the Cantinesi Forests ${ }^{10}$. This approach allowed us to calculate the benefit from hunting activity as per formula 8:

$$
\mathrm{B}_{\mathrm{av}}=\mathrm{DAP}_{\mathrm{atc}} * \mathrm{~S}_{\mathrm{ci}} / \mathrm{S}_{\mathrm{atci}}
$$

where:

$\mathrm{B}_{\mathrm{av}}=$ hunting activity benefit;

$\mathrm{DAP}_{\text {atc }}=$ average willingness to pay per ATC;

$\mathrm{S}_{\mathrm{ci}}=$ hunting surfaces of the study area $\mathrm{i}$;

$\mathrm{S}_{\text {atci }}=$ hunting surfaces of the ATC $i$.

In view of such hunting areas the estimated annual values of hunting activity is around 61.500 euro for the area of Grafagnana and around 4.280 euro for the Casentinesi Forests.

\footnotetext{
${ }^{8}$ As per the previous cases the values have been adjusted to match the up-dated tables of the ACI 2011.

${ }^{9}$ Garfagnana = ATC Lucca 11 e 12, Casentino = ATC Arezzo 1.

${ }^{10}$ Such difference in acres between the hunting surfaces is due to the numerous no-hunting zones promoted by the National Park establishment.
}

\subsection{Total Recreational Touristic Benefit $\left(B_{\text {trt }}\right)$}

The total annual recreational touristic benefit was finally estimated by adding to the touristic benefits $\left(B_{t}\right.$, Section 4.1), those relative to hunting activity ( $B_{a v}$, Section 4.2). Table 1 shows the results.

\section{Conclusions}

To evaluate a good means to measure its ability to generate utility; i.e. to meet the needs of its users. The economic system based on exchange and currency, expresses the value of all goods in terms of price; i.e. the amount of money needed to exchange the asset.

However, different issues with respect to economic goods are inherent in the estimation of environmental goods, due to the lack of direct reference to the market. Natural systems are multifunctional assets able to provide human being a wide range of goods and services of economical value [19]. More particularly, forests systems compound a very complex series of functions. Among the principal functions is the production of wood, the hydro-geological protection, the conservation of particular habitats, the recreational touristic function, and so on.

Large amounts of money are spent, in Tuscany, every year for forests' preservation. This is documented through the implementation of interventions pre-established by the Regional Forest Program. At first glance, it is difficult for the public administrations or other competent bodies, to develop a budget of this activity, mainly because the estimation of the value of wooded land entails, as mentioned earlier, the analysis of issues which estimation is difficult to determine. Although it is possible to quantify the existing wood mass and potential gains from the variety of woods, it is more complex to estimate the value of the other functions performed in the natural forests areas. Accordingly, the importance of this study is in the fact that it allows developing a value analysis, of the recreational touristic benefit, often overlooked when considering a forested area. The recreational touristic benefit estimation should therefore be included in a holistic study of forests' heritage to assess the relationship between benefits and costs of this resource.

The methodology of the Benefit Transfer based on a literature review of existing analysis relevant to the issues discussed was adopted: the main advantage of this methodology is that it adopts an existing analysis, avoiding therefore the development of a new one and saving considerable time and resources. On the other hand a strong correlation between the results of the Benefit transfer and the quality of the original data analysis can be identified. It is also important not to forget the fact that the context of the study site, as such, is unlikely to be comparable to the policy site due to a variety of elements ranging from the presence of any substitute goods 
at the level of population income (especially in the context of international transfer of benefits), from the temporal context to the biophysical context. The studies selected in this work of "study site" are based on the methodologies of travel cost and Contingent Valuation. The approaches appear to be structured on a broad basic theory, although there are some disadvantages that must be considered in dealing with the end result. The Travel Cost Method tends to identify values that often underestimate the considered asset because it does not appraise certain typical environmental goods' values: the option values and existence values. Regarding the Contingent Valuation, the principal problem lies essentially in the psychological attitude of the respondent and to the structuring of the questionnaire. Three types of distortions are identified: the strategic distortion is relative to a tendency to minimize the utility of the good or service to avoid a successive payment for its improvement, or it is relative to a tendency to please the respondent. The informative distortion is due to an erroneous understanding of the question and of the context resulting in the attribution of a generic value to the good. Finally, the instrumental distortion is relative to an order of magnitude suggested by the interviewer and conditioning therefore the respondent, or when the asset being evaluated can be compared with other goods [20].

For the present work, based on available data, two areas were chosen representing similar environmental characteristics. However, the two areas presented different management scenarios, given the standards of protection the National Park of the Casentinesi Forested must follow. This is also highlighted and confirmed by the sensibly lower hunting activity with respect to the Grafagnana wooded areas. Despite this, the recreational touristic value is greater in the Casentinesi Forests. This is probably because it was included to a circuit, the National Parks, greatly advertised, and able to attract a larger number of users.

\section{REFERENCES}

[1] M. Clawson and J. L. Knetch, "Economics of Outdoor Recreation,” The Johns Hopkins University Press, Baltimore, 1966.

[2] J. P. Hoehn and A. Randall, "A Satisfactory Benefit Cost Indicator from Contingent Valuation,” Journal of Environmental Economics and Management, Vol. 14, No. 2, 1987, pp. 226-247. doi:10.1016/0095-0696(87)90018-0

[3] D. Pearce and C. Pearce, "The Value of Forest Ecosystems: A Report to the Secretariat Convention on Biological Diversity,” University College London, London, 2001.

[4] D. Pettenella and L. Secco, "Prospettive di Mercato per la
Produzione Fuori Foresta,” Foreste ed Alberi Oggi, Vol. 128, 2006, pp. 15-20.

[5] S. Navrud and R. Brouwer, "Good Practise Guidlelines in Benefis Transfer of Forest Externalities,” COST Action E45, European Forest Externalities, Euroforex, 2007.

[6] T. Tempesta and F. Marangon, "Stima del Valore Economico Totale dei Paesaggi Forestali Italiani Tramite Valutazione Contingente,” Genio Rurale, Vol. 11, 2004, pp. 32-45.

[7] T. L. Saaty, “The Analytic Hierarchy Process: Planning, Priority, Setting and Resource Allocation,” Mac Graw-Hill, New York, 1980.

[8] V. Gallerani, G. Zanni and D. Viaggi, "Valutazione di Impatto Ambientale,” Manuale di Estimo, Mc Graw-Hill, Milano, 2004, pp. 260-265.

[9] P. Nijkamp and P. Rietveldt, "Multiple Objective Decision Analysis in Regional Economic," Handbook of Regional and Urban Economics, Amsterdam, 1996.

[10] J. Malczewski, "GIS and Multicriteria Decision Analysis,” John Winley \& Sons, Inc., New York, 1999.

[11] R. K. Shrestha and J. B. Loomis, "Testing a Meta-Analysis Model for Benefit Transfer in International Outdoor Recreation,” Ecological Economics, Vol. 39, No. 1, 2001, pp. 67-83. doi:10.1016/S0921-8009(01)00193-8

[12] O. Ciancio, P. Corona, M. Marinelli and D. Pettenella, "Valutazione dei Danni da Incendi Boschivi," Collaborazione con Accademia Italiana di Scienze Forestali e Corpo Forestale dello Stato, Coppini, Firenze, 2007.

[13] D. N. Barton, "The Transferability of Benefit Transfer: Contingent Valuation of Water Quality Improvements in Costa Rica,” Ecological Economics, Vol. 42, No. 1-2, 2002, pp. 147-164.

[14] A. Marinelli, L. Casini and D. Romano, "Valutazione Economica Dell'impatto Aggregato e dei Benefici Diretti Della Ricreazione All'aperto di un Parco Naturale Della Toscana,” Genio Rurale, Vol. 9, 1990, pp. 51-58.

[15] M. Clawson, "Methods of Measuring the Demand and Value of Outdoor Recreation,” Resource of the Future, Washington DC, 1959.

[16] M. Merlo, "Una Valutazione Della Funzione Ricreazionale Dei Boschi,” Rivista di Economia Agraria, Vol. 37, No. 2, 1982, pp. 385-397.

[17] M. Rossi, "La Valutazione Economica Della Grande Escursione Appenninica in Casentino: Un'applicazione del Trave Cost Method,” University of Florence, Florence, 1991.

[18] A. Marinelli and S. Romano, "La Valutazione Economica dei Benefici e Dell'impatto Aggregato Della Caccia Nella Provincia di Firenze,” Giunti Editore, Firenze, 1997.

[19] D. Pearce, K. Turner and I. Bateman, "Economia Ambientale,” Editore il Mulino, 2003

[20] E. Kula, "Economics of Natural Resources, the Environment and Policies," Chapman \& Hall, London, 1994. doi:10.1007/978-94-011-6037-7 